\title{
The issue of ensuring the safe explosion of the spent orbital stages of a launch vehicle with propulsion rocket engine
}

\author{
Valeriy I. Trushlyakov ${ }^{1, *}$, Konstantin I. Zharikov ${ }^{1}$ \\ ${ }^{1}$ Omsk State Technical University, 644050 Omsk, Russia
}

\begin{abstract}
A method for increasing the safe explosion of the spent orbital stages of a space launch vehicle (SLV) with a propulsion rocket engine (PRE) based on the gasification of unusable residues propellant and venting fuel tanks. For gasification and ventilation the hot gases used produced by combustion of the specially selected gas generating composition (GGC) with a set of physical and chemical properties. Excluding the freezing of the drainage system on reset gasified products (residues propellant+pressurization gas+hot gases) in the near-Earth space is achieved by selecting the physical-chemical characteristics of the GGC. Proposed steps to ensure rotation of gasified products due to dumping through the drainage system to ensure the most favorable conditions for propellant gasification residues. For example, a tank with liquid oxygen stays with the orbital spent second stage of the SLV "Zenit", which shows the effectiveness of the proposed method.
\end{abstract}

\section{Introduction}

According to [1], $36 \%$ of explosions in near-Earth space are associated with the destruction of explosive fuel tanks, due to existing residual pressure in the fuel tank and the fuel component of the unused residues. Pressurized gas boost fuel tanks are subjected to thermal loading, thereby increasing the internal pressure in the fuel tanks and lines due to the expansion of the gas and the evaporation of the fuel component of the unused residues.

In the growth process of the internal pressure in the fuel tanks and lines, the failure stress of the construction material increases, reaching values exceeding the strength of the construction material, which leads to explosions. Reduction of strength of the material structure of the fuel tanks, other than increasing the temperature, act as contributory factors in space: corpuscular beams, ultraviolet radiation, solar flares, etc. [2].

The analysis of the destruction of the fuel tanks' upper stages contributed to the introduction of international organizations' (IADC, COPUOS) [3] effective measures to reduce explosions in near-Earth space: making the energy stored in the spent stage passive, the removal of unused fuel component residues [4, 5], withdrawal from orbit $[6,7]$, and the drainage of excess gas turbocharging. However, when resetting the vapor mixture, for example, oxygen from the fuel tank (vapors' oxygen and pressurization gas-helium)

\footnotetext{
*Corresponding author: vatrushlyakov@yandex.ru
} 
through the drainage system into the surrounding space, there is a sharp decrease in pressure and decrease in gas temperature, which leads to condensation of vapor from the oxygen and its freezing, which results in the drain pipe freezing.

\section{Formulation of the problem}

In order to ensure the safe explosion of the orbital spent stage of SLV with undeveloped remnants of propellant the following steps are invited to be implemented:

a) selecting the composition of GGC combustion products which flow as a result of the fuel tank that will not interact with liquid propellant unusable residues;

b) upon reaching the predetermined pressure in the fuel tank, as determined by its strength, provide relief obtained by gasification products (evaporated remnants of propellant+pressurization gas+composition of combustion of the GGC) through the drainage system in the near-Earth space;

c) selection of physical-chemical parameters of the GGC to provide gasification conditions of the unusable propellant residues and preservation of the gaseous phase of the propellant vapor when resetting gasification products through the drainage system;

d) due to the discharge of gasified products through the drainage system to make a turn of the orbital spent stage of SLV to ensure the most favorable conditions for gasification of liquid propellant residues in feeding the hot gas tank.

\section{The criteria for selecting the composition of the GGC}

The source of the heat carrier (HC) supplied to the fuel tank are hot gases-products of the combustion of the GGC.

At this point in the missile industry a different GGC $[8,9]$ has been used for more than a decade with the desired characteristics and to select the optimal of the GGC and consequently reception of $\mathrm{HC}$ a number of requirements must be entered:

1) Products of combustion in the GGC must not react chemically with the propellant component, nor gas pressurization - $\left(\mathrm{G}_{\mathrm{I}}\right)$;

2) Products of combustion in the GGC must not be composed of the gas product converted into the solid phase at the boiling temperature of oxygen $(90-120 \mathrm{~K})-\left(\mathrm{G}_{\mathrm{II}}\right)$;

3) The $\mathrm{HC}$ must have a maximum thermal capacity - $\left(\mathrm{G}_{\mathrm{III}}\right)$;

4) To transfer the maximum amount of heat in the unusable propellant residues - HC should have the lowest molecular weight $-\left(\mathrm{G}_{\mathrm{IV}}\right)$.

Table 1 lists the possible compositions of the GGC formally satisfying the above requirements, similar to the compositions described in [10-15], and the composition temperature of the $\mathrm{HC}$, calculated in the software package [16] at a pressure of $2.5 \mathrm{~atm}$.

Table 1. Products of compositions of the GGC, the temperature products of combustion of the GGC, including the condensed phase (s) remaining in the gas generator.

\begin{tabular}{|c|c|c|c|c|}
\hline № & Investigation of the GGC & $\begin{array}{c}\text { Temperature } \\
\text { products of } \\
\text { combustion, } \mathrm{K}\end{array}$ & $\begin{array}{c}\text { Number of } \mathbf{H C} \\
\text { required for } \\
\text { gasification of } \\
\mathbf{1} \text { kg of liquid } \\
\text { oxygen, } \mathbf{k g}\end{array}$ & $\begin{array}{c}\text { Number of } \\
\text { GGC required } \\
\text { for gasification } \\
\text { of 1 kg of } \\
\text { liquid oxygen, } \\
\mathbf{~ k g}\end{array}$ \\
\hline 1 & $64.7 \% \mathrm{NaN}_{3}+35.3 \% \mathrm{KMnO}_{4}$ & 1515 & 0.074 & 0.18 \\
\hline 2 & $67.6 \% \mathrm{NaN}_{3}+33.4 \% \mathrm{CrO}_{3}$ & 1798 & 0.059 & 0.14 \\
\hline 3 & $50 \% \mathrm{NaN}_{3}+50 \% \mathrm{Fe}_{2} \mathrm{O}_{3}$ & 1125 & 0.109 & 0.34 \\
\hline 4 & $60 \% \mathrm{NaN}_{3}+40 \% \mathrm{CaO}_{2}$ & 1740 & 0.062 & 0.154 \\
\hline
\end{tabular}




\begin{tabular}{|c|c|c|c|c|}
\hline 5 & $\begin{array}{c}64 \% \mathrm{NaClO}_{3}+26 \% \mathrm{BaO}_{2}+6 \% \\
\mathrm{SiO}_{2}+4 \% \mathrm{Mg}\end{array}$ & 1466 & 0.081 & 0.28 \\
\hline 6 & $\begin{array}{c}86 \% \mathrm{NaClO}_{4}+10 \% \mathrm{Na}_{2} \mathrm{O}_{2}+4 \\
\% \mathrm{Si}\end{array}$ & 1480 & 0.081 & 0.19 \\
\hline 7 & $\begin{array}{c}77.5 \% \mathrm{NaClO}_{4}+ \\
17 \% \mathrm{CaO}_{2}+5.5 \% \mathrm{Mg}\end{array}$ & 1457 & 0.082 & 0.20 \\
\hline 8 & $\begin{array}{c}78 \% \mathrm{NaClO}_{3}+7 \% \mathrm{BaO}_{2}+4 \% \\
\mathrm{SiO}_{2}+9.5 \% \mathrm{Fe}+1.5 \% \mathrm{Mg}\end{array}$ & 1475 & 0.081 & 0.26 \\
\hline
\end{tabular}

\section{Technology of gasification process in the tank for the spent stage of the space launch vehicle}

The basic technology of the process of gasification of the residual propellant in the fuel tank of liquid oxygen in the sample stage of the SLV is implemented in the following sequence: after turning off the main propellant rocket engine to the fuel tank from the remnants of propellant (liquid and vapor phase) the pressurization gas with total pressure of about $3 \mathrm{~atm}$ is served of the $\mathrm{HC}$ with a temperature of $1100-1700 \mathrm{~K}$ and speed of about 900 $\mathrm{m} / \mathrm{s}$ [4].

As a result of the heating and evaporation of the liquid phase of the propellant, the pressure increases, the temperature gradient is aligned to the thermodynamic system "products of combustion the GGC+vaporized residual propellant+gas helium pressurization".

In the future, we are considering the possibility of heat transfer from the gas generator housing to the drainage system via the heat bridge to prevent freezing of the vapor on the inner surface of the drainage pipe (see. Fig. 1).

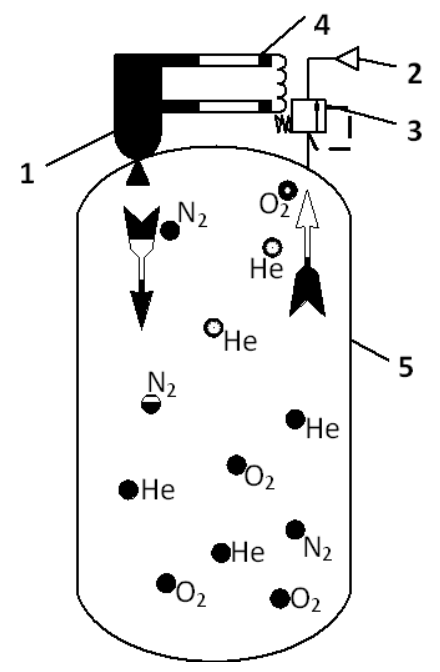

Fig. 1. Schematic diagram of the installation of the gas generator on the fuel tank and drainage system: 1 - gasifier of the GGC; 2 - nozzle reset gasification products from the tank; 3 - drain-safety valve; 4 - thermal bridge for the transfer of residual heat from the gas generator to the drainage system; 5 - fuel tank.

\section{The process of releasing gasification products into the environment}


Upon reaching the opening pressure of the drain-safety valve the gasification products of the fuel tank are released into the environment. For example, the fuel tank of liquid oxygen of the second stage of the SLV "Zenit" held a preliminary assessment of the thermal loading of the fuel tank [17] and input of the HC to the fuel tank [18].

The curves of change in partial oxygen pressure, shown in Fig. 2, deliver the supply efficiency of the $\mathrm{HC}$ to the fuel tank.

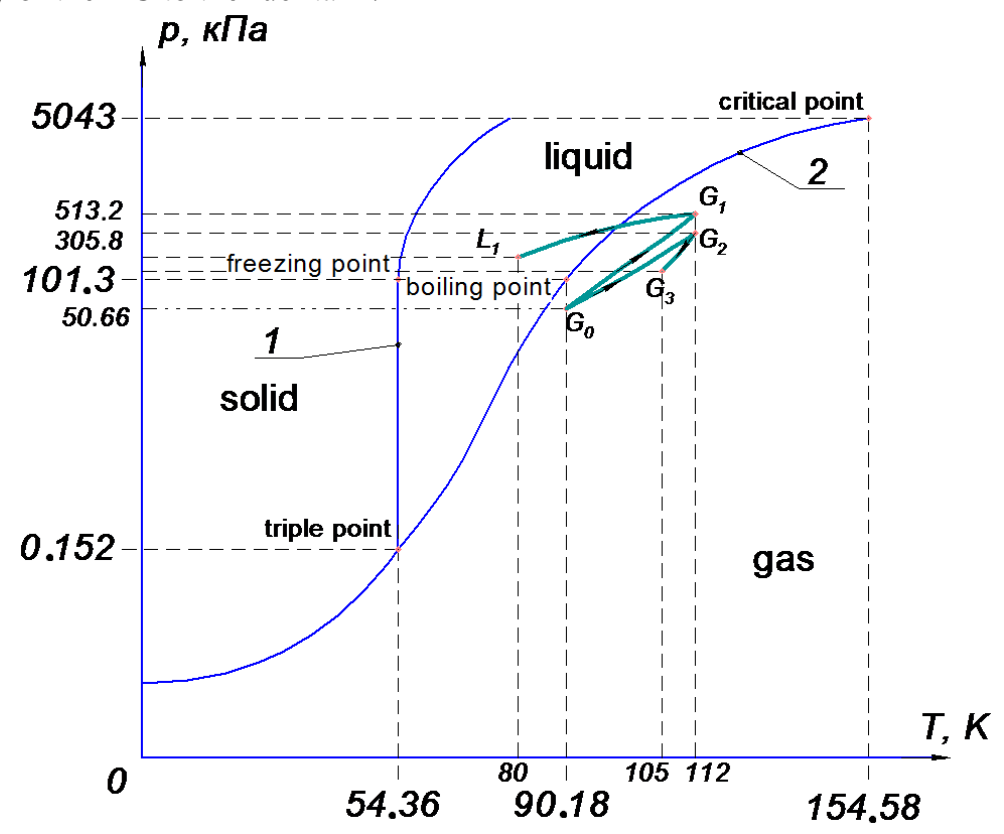

Fig. 2. Phase diagram and the phase equilibrium line: 1 - solid and liquid states; 2 - liquid and gas states; the values of the partial pressures: $G_{0}-$ at the time off the main propellant rocket engine; $G_{1}$ - the thermal loading of the fuel tank; $G_{2}$ - the entering of the HC; $L_{1}$ - release of the gasvapor mixture; $G_{3}$ - release of gasification products.

\section{Conclusions}

1. Provide safe explosion of the spent orbital stage of the space launch vehicle with unusable remnants of the liquid propellant in the tanks is proposed to be carried out on the basis of ventilation by means of hot gases produced by the combustion of the GGC.

2. Prevention of the freezing of the drainage system on release of the gasification products (vaporized residual propellant + residues pressurization gas + hot gases) into the surrounding space is achieved through the selection of physical-chemical properties.

3. The most effective of GGC are oxygen or nitrogen generation HC № 2 and 4.

4. The use of reactive energy discharged gasification products allows for the most favorable boundary conditions of liquid propellant in the tanks for the process of gasification.

Research carried out with the financial support of the Ministry of Education of Russia, agreement №14.577.21.0157 from 28.11.2014, (unique identifier RFMEFI57714X0157). 


\section{References}

1. Tech. Report on Space Deb., A/AC.105/720 [Internet]. [Cited 2016 Oct 21]. Available from: http://www.orbitaldebris.jsc.nasa.gov/library/references.html.

2. B. A. Campbell, S. W. McCandless jr., Introduction to space sciences and spacecraft applications (Gulf Professional Publishing, 1996)

3. Update of the IADC space deb. mitigation guidelines. IADC-11-02. Beijing, May (2014)

4. V. I. Trushlyakov, D. B. Lempert, M. E. Bel'kova, Combust. Explo. Shock 51, 326 (2015)

5. Report by the Secretariat. Committee on the Peaceful Uses of Outer Space [Internet]. [Cited 2016 Sep 15]. Available from: http://www.unoosa.org/pdf/reports/ac105/AC105_620R.pdf

6. V. T. Trushlyakov, Ya. T. Shatrov, Flight 7 (2014)

7. K. Takase, M. Tsuboi, S. Mori, K. Kobayashi, Mitsubishi Heavy Industries Technical Review 48, 11 (2011)

8. D. B. Lempert, G. N. Nechiporenko, G. B. Manelis, Combust. Explo. Shock 47, 45 (2011)

9. S. Pourmortazavi, S. Hajimirsadeghi, I. Kohsari, M. Fathollahi, S. Hosseini, Fuel 87, $244(2008)$

10. N. Matsuda, N. Hirata, S. Iyoshi, Patent 5780767 US (1995)

11. V. D. Sasnovskaya, A.P. Razumova, V. V. Aleshin, Patent 2052283 RF (1993)

12. I. A. Smirnov, A. T. Logunov, V. V. Shapovalov, V. I. Vanin, Patent 2149136 RF, (1998)

13. A. Ya. Malyshev, Ye. V. Levakov, A. A. Tatynov, V. K. Raevskiy, A. I. Sivertsev, Patent 2151735 RF, (1998)

14. H. Ellern, Modern Pyrotechnics: Fundamental Journal of Applied Physics (Chemical Publishing Company Inc., New York, 1961)

15. A. A. Shidlovskiy, Principles Of Pyrotechnics (Mashinostroenie, Moscow, 1973)

16. B. G. Trusov, The XIV Int. Symp. on Chemical Thermodynamics (MGTU, Moscow, 2002)

17. V. I. Trushlyakov, K. I. Zharikov, Fire and Explosion Saf. 25, 7 (2016)

18. V. V. Shalai, V. I. Trushlyakov, V. Yu. Kudentsov, Thermal processes in the art 6, 67 (2014) 